\section{OPEN ACCESS}

Edited by:

Jianguang Ji,

Lund University, Sweden

Reviewed by:

Xiangqian Guo,

Henan University, China

Stephen Marc Schwartz,

Fred Hutchinson Cancer Research

Center, United States

*Correspondence:

Fu Chen

fuchen@scdc.sh.cn

Yao Yang

yangyao_6@hotmail.com

${ }^{+}$Co-first authors

Specialty section:

This article was submitted to Cancer Epidemiology and Prevention,

a section of the journal

Frontiers in Oncology

Received: 15 January 2019 Accepted: 05 July 2019

Published: 17 July 2019

Citation:

Pingping B, Yuhong Z, Weiqi L, Chunxiao W, Chunfang W, Yuanjue S, Chenping Z, Jianru X, Jiade L, Lin K, Zhengdong C, Weibin Z, Chen F and Yang Y (2019) Incidence and Mortality

of Sarcomas in Shanghai, China,

During 2002-2014.

Front. Oncol. 9:662.

doi: 10.3389/fonc.2019.00662

\title{
Incidence and Mortality of Sarcomas in Shanghai, China, During 2002-2014
}

\author{
Bao Pingping ${ }^{1+}$, Zhou Yuhong ${ }^{2 t}$, Lu Weiqi ${ }^{3+}$, Wu Chunxiao ${ }^{1}$, Wang Chunfang ${ }^{1}$, \\ Sun Yuanjue ${ }^{4}$, Zhang Chenping ${ }^{5}$, Xiao Jianru ${ }^{6}$, Lu Jiade ${ }^{7}$, Kong Lin ${ }^{7}$, Cai Zhengdong ${ }^{8}$, \\ Zhang Weibin ${ }^{9}$, Fu Chen ${ }^{10 *}$ and Yao Yang ${ }^{11 *}$
}

\begin{abstract}
${ }^{1}$ Department of Cancer Control and Prevention, Shanghai Municipal Center for Disease Prevention and Control, Shanghai, China, ${ }^{2}$ Department of Medical Oncology, Zhongshan Hospital, Fudan University, Shanghai, China, ${ }^{3}$ Department of General Surgery, Zhongshan Hospital, Fudan University, Shanghai, China, ${ }^{4}$ Department of Medical Oncology, Sixth People's Hospital South Campus, Shanghai Jiaotong University School of Medicine, Shanghai, China, ${ }^{5}$ Department of Oral and Maxillofacial Surgery, Shanghai Ninth People's Hospital, Shanghai Jiaotong University School of Medicine, Shanghai, China, ${ }^{6}$ Department of Bone Tumor Surgery, Shanghai Changzheng Hospital, Shanghai, China, ${ }^{7}$ Department of Radiation Oncology, Shanghai Proton and Heavy lon Center, Shanghai Cancer Hospital, Fudan University, Shanghai, China, ${ }^{8}$ Department of Orthopedics, Shanghai General Hospital, Shanghai Jiaotong University School of Medicine, Shanghai, China, ${ }^{9}$ Department of Orthopedics, Shanghai Ruijin Hospital, Shanghai Jiaotong University School of Medicine, Shanghai, China, ${ }^{10}$ Shanghai Municipal Center for Disease Prevention and Control, Shanghai, China, " Department of Medical Oncology, Shanghai Jiao Tong University Affiliated Sixth People's Hospital, Shanghai, China
\end{abstract}

Background: Sarcomas are a heterogeneous group of rare but deadly malignant tumors. The aim of this study was to comprehensively describe the incidence and mortality of sarcomas in Shanghai during 2002-2014.

Method: Data were from Shanghai Cancer Registry. All new cases diagnosed with sarcomas and all death records where the cause of death listed as sarcomas were included. The characteristics of sarcomas incidence and mortality were analyzed. Age-standardized rates (ASRs) were adjusted by the world standard population. The trends were assessed by Joinpoint analysis.

Results: A total of 9,440 incident cases were identified. The ASR was $3.4 / 10^{5}$ for all sarcomas combined. Incidence of sarcomas overall was similar in females $\left(3.5 / 10^{5}\right)$ as in males $\left(3.4 / 10^{5}\right)$. Except for sarcomas "Not Otherwise Specified" (NOS), the most common histological subtype was gastrointestinal stromal sarcoma (GISS) (14.8\%), which was followed by fibrosarcoma (7.2\%), lipoblastoma (6.7\%), leiomyosarcomas (6.5\%), and osteosarcoma (5.3\%). Among those incident cases, $87.9 \%$ were located in soft tissue sarcomas (STS) and $12.1 \%$ in bone and joint (bone sarcomas). The ASRs for STS and bone sarcomas were $2.8 / 10^{5}$ and $0.6 / 10^{5}$, respectively. Incidence rates for all STS combined rose exponentially with age, while bone sarcomas had the highest incidence at age $0-19$.

There were 4,279 deaths during 2002-2014 with the ASR of 1.3/105. Age-adjusted mortality due to sarcomas was slightly higher in males $\left(1.5 / 10^{5}\right)$ than females $\left(1.2 / 10^{5}\right)$. Except for sarcomas NOS, leiomyosarcomas was the most common subtype, comprising $9.9 \%$ of deaths due to sarcomas, followed by lipoblastoma $(6.4 \%)$ and osteosarcoma (6.3\%). The ASRs of mortality for STS and bone sarcomas were 1.0/10 and $0.2 / 10^{5}$, respectively. 
For both males and females, the age-standardized incidence for STS and bone sarcomas did not change meaningfully over the study period. In contrast, age-standardized STS mortality in females increased by $2.3 \%$ per year (95\% Cl: $0.3,4.4 \%)$, but was unchanged in males. No meaningful trends in bone sarcomas mortality were observed for either males or females.

Conclusion: This population-based study was the first report of epidemiology of sarcomas in Shanghai according to anatomic site and histologic type. The diversity and rarity of sarcomas suggested more detailed data are warranted.

Keywords: sarcoma, incidence, mortality, epidemiology, population-based cancer registry

\section{INTRODUCTION}

Sarcomas, a heterogeneous group of rare malignant tumors arising from mesenchymal cells, account for about $1 \%$ of all new malignancies diagnosed $(1,2)$. These tumors can occur at any age and in almost any anatomic site. In relation to the anatomy, there have two types of common and distinct sarcomas: sarcomas from bone and joint (bone sarcomas) and soft tissue sarcomas (STS). Based on the histology, more than 50 distinct histological sarcoma subtypes exist according to the classification of the World Health Organization (WHO) updated in 2002 (3). It's difficult to obtain the precise estimates of sarcomas and sarcoma subtypes. The patterns of incidence and mortality of sarcomas have little been studied $(1,4,5)$. Sarcomas, although relatively rare, are quite deadly and disproportionately affect younger population. STS are reported to account for, respectively, $0.7-1 \%$ and $4-8 \%$ of all adult and pediatric malignant tumors, and bone sarcomas for, respectively, $0.2 \%$ and $5 \%$ in most comprehensive reviews (1, 6-8).

Sarcomas can originate from any organ, tissue, bone, or cartilage. STS diagnoses predominate over bone sarcoma diagnoses with about 4:1 incidence ratio (5). A study on sarcomas of all types combined from RARECARE project showed that $84 \%$ were STS and $14 \%$ were bone sarcomas, of which age-standardized incidence of STS was $4.2 / 10^{5}$ and that of bone sarcomas was $0.8 / 10^{5}$ in Europe (4). In Surveillance, Epidemiology, and End Results (SEER) program data, STS also occurred much more frequently than bone sarcomas, which accounted for nearly $87 \%$ and $13 \%$ in 2008 , respectively (1). No population-based mortality data have been reported before.

The causes of most sarcomas are unknown. Environmental factors, including ionizing radiation, occupational exposure to certain chemicals such as herbicide, have been associated with increased risk of specific types of sarcomas. Several heritable syndromes are associated with the development of some sarcomas [e.g., heritable retinoblastoma, neurofibromatosis 1, Li-Fraumeni syndrome (LFS)] $(5,9)$.

The aim of this paper is to examine incidence, mortality, and the temporal trends for sarcomas in Shanghai from 2002 through 2014, based on a population-based cancer registry, according to anatomic site and histologic type/subtype, using the most recent criteria of the WHO classification (10). These population-based data will be important in furthering our understanding of the morphologic and genetic diversity of sarcomas.

\section{METHODS}

Population-based cancer incidence and mortality data were derived from the Shanghai Cancer Registry (SCR), a member of the International Association of Cancer Registries (IACR). SCR has been a regular contributor to the Cancer Incidence in Five Continents (CI5) published by the IARC and the data have been published in the last seven volumes of CI5. Details of the cancer registry have been previously described $(11,12)$. Briefly, the SCR has formed standard system to collect, process, and report cancer incidence data. A standardized notification card, which includes information on name, date of birth, gender, address, occupation, primary site of cancer, histopathology, incidence date, basis of cancer diagnosis, and reporting hospital is used for reporting cancer cases. Death certificates have been used to gather information on unregistered cancer patient and all death cases due to sarcoma based entirely on vital statistics records during the time period have been included in SCR. The data for incidence and mortality of sarcomas during this period were complete in this study. The completeness of coverage of the Registry is very high with death certification only (DCO) $<1 \%$. Sarcomas cases (including second primary cancers with $0.5 \%$ ) from soft tissues or bone, diagnosed among residents of Shanghai during 2002-2014, were included in this study.

Primary site and histological type were coded according to the third edition of the International Classification of Disease for Oncology (ICD-O-3) and then categorized into major histological types and subtypes of sarcoma as shown in Table $\mathbf{1}$. In brief, the cancers described in this manuscript include all sarcomas from soft tissue and from bone, including ICD-O-3 M codes 8800-8935, 8910, 8920, 8936, 8940, 8950-8959, 8963-8964, 8990-8991, 9020-9044, 9120-9133, 9150, 9170, 9180-9251, 92609261, 9364-9372, 9540-9581 combined with all ICD-O-3 T codes (C00-C80). There were 546 cases from C49 with M 8000-8004 included in this study. Finally, a total 9,440 incident cases and 4,279 death cases that met these criteria were included in the study. The percentage of histologically verified cases (MV\%) was $94.4 \%$ and the death certificate only (DCO) \% was $0.15 \%$.

The corresponding population data of Shanghai urban areas were retrieved from the Shanghai Municipal Bureau of Public 
TABLE 1 | Histological group of sarcomas by ICD-O-3 code.

\begin{tabular}{ll}
\hline Histological group & ICD-O-3 codes \\
\hline Sarcoma NOS & M8800-8806, M8000-8004 located in C49 \\
Osteosarcoma & M9180-9195 \\
Chondrosarcoma & M9220-9243 $9261,9364,9471,9473,9474$ \\
Ewing's sarcoma \& PNET & M9250-9252 \\
Giant cell sarcoma & M8850-8858 \\
Lipoblastoma & M8810-8815 \\
Fibrosarcoma & M8830 \\
Malignant fibrohistiocytoma & M8832,8833 \\
Dermatofibrosarcoma protuberans & M8710, 9120-9133, 9150, 9170 \\
Vascular sarcoma & M8900-8920 \\
Rhabdosarcoma & M8890-8896 \\
leiomyosarcomas & M8936 \\
Gastrointestinal stromal sarcoma & M9270, 9290, 9310, 9330 \\
Ameloblastoma & M9540-9571 \\
Malignant peripheral nerve sheath & \\
tumor (MPNST) & M9040-9043 \\
Synovial sarcoma & M8930-8935 \\
Stromal sarcoma & M8964,9044 \\
Clear cell sarcoma & M8840 \\
Myxosarcoma & M8990 \\
Malignant mesenchymoma & M9991 \\
Embryonic sarcoma & M9580 \\
Kaposi's sarcoma & Granulosa cell sarcoma \\
Alveolar soft part sarcoma (ASPS) & M \\
\hline
\end{tabular}

NOS, not otherwise specified; PNET, primitive neuroectodermal tumors.

Security every year. Between 2002 and 2014, Shanghai had a total population of inhabitants $179,955,231$. The study was approved and the need for consent was waived by the institutional review board (IRB) of Shanghai Municipal Center for Disease Control and Prevention. In this study, only data in annual cancer report was used and no information to identify individual subjects was included.

The relative frequency was calculated as the percentage contribution of each particular group or subgroup to the total case series. The incidence rate was the number of new cases divided by the population at risk and was expressed as the number per 100,000 at risk and was age-adjusted by the direct method using the weight of the 1960 world standard population (13). The annual percent changes (APCs), representing the average percent increase or decrease in cancer rates per year over a specified period of time, were obtained using the joinpoint regression analysis. The joinpoint analysis has been widely applied to detect the changes points (joinpoints) and determine the trends between join points, which involves fitting a series of joined straight lines on a logarithmic scale to the trends in annual age-standardized rates (ASRs) (14). The allowed maximum number of joinpoints was one over 13 years as at least 5 years was required for each segment. We used a Joinpoint regression model implemented in the Joinpoint Regression Program (Version 4.5.0.1), which was developed by the Surveillance, Epidemiology, and End Results Program of the US National Cancer Institute (15).

\section{RESULTS}

\section{Incidence}

During 2002-2014, 4,503 (47.7\%) males and 4,937 (52.3\%) females were diagnosed with sarcomas. The crude annual incidence rate (CR) was $5.3 / 10^{5}$ and the ASR was $3.4 / 10^{5}$. Incidence of sarcomas overall was similar in females $\left(3.5 / 10^{5}\right)$ as in males $\left(3.4 / 10^{5}\right)$. The number of cases, percent distribution, age distribution, and incidence rates according to the histological group were shown in Table 2. About 3.9\% of sarcomas occurred in children and adolescents (0-19 years), while majority $(60.9 \%)$ occurred in the $20-64$ years age group. The remaining $35.2 \%$ occurred in the elderly aged over 65 years. The most common histological subtype was gastrointestinal stromal sarcoma (GISS, malignant GISTs, 14.8\%), which was followed by fibrosarcoma (7.2\%), lipoblastoma (6.7\%), leiomyosarcoma $(6.5 \%)$, and osteosarcoma (5.3\%). It should be noted that $31.2 \%$ of total cases were sarcomas "Not Otherwise Specified" (NOS). Kaposi sarcoma was very rare in Shanghai with only 14 cases during this whole period. In females, the incidence of stromal sarcoma (ASR $0.2 / 10^{5}$ ), the fifth common subtype, was apparently higher than in males (ASR $0.02 / 10^{5}$ ).

Incidence rates of sarcomas overall increased with age following a modest peak in adolescents. Incidence rates for all STS combined rose exponentially with age, while bone sarcomas had the highest incidence at age 0-19. Among the histological categories, osteosarcoma was the most frequent at age $0-19$, with the peak of incidence of $0.5 / 10^{5}$. Rhabdosarcoma was the second frequent at this age group. Liposarcoma rates were very low in children and adolescents and then rose exponentially before peaking in the elderly. GISS incidence cases were rare before 40 years old and had the highest incidence at age 65+ group. Leiomyosarcoma incidence rates in females had two peaks at age group of 45-49 and 75-79, respectively.

As Table 3 shown, among those newly diagnosed cases, $87.9 \%$ were located in STS and $12.1 \%$ in bone and joint (bone sarcomas).The CR and ASR were $4.6 / 10^{5}$ and $2.8 / 10^{5}$ for STS, $0.6 / 10^{5}$ and $0.6 / 10^{5}$ for bone sarcomas, respectively. About one-third (32.2\%) of STS were located in the connective, subcutaneous and other soft tissues (ICD-10: C49), followed by digestive organs (31.4\%), and female genital organs (8.6\%).

For STS, except for the sarcomas NOS, the most common histological subtype was GISS (16.8\%), which was followed by fibrosarcoma (7.7\%), lipoblastoma (7.5\%), leiomyosarcoma (7.3\%), and malignant peripheral nerve sheath tumor (MPNST) (5.1\%). For bone sarcomas, osteosarcoma (43.0\%), giant cell sarcoma (17.4\%), and chondrosarcoma (16.1\%) were the most three subtypes.

\section{Mortality}

There were 4,279 death cases with sarcomas in Shanghai during 2002-2014, 2,191 (51.2\%) for males and 2,088 (48.8\%) for females, respectively. The crude annual mortality rate was $2.4 / 10^{5}$ and the mortality rate adjusted by the world standard population 
TABLE 2 | Incidence of sarcomas by age, gender, and histologic type, Shanghai, 2002-2014.

\begin{tabular}{|c|c|c|c|c|c|c|c|c|c|c|c|c|c|c|c|c|}
\hline \multirow[t]{3}{*}{ Histologic group } & \multicolumn{8}{|c|}{ Male } & \multicolumn{8}{|c|}{ Female } \\
\hline & \multirow[b]{2}{*}{$N$} & \multirow[b]{2}{*}{$\%$} & \multicolumn{6}{|c|}{ Incidence rates $(1 / 100,000)$} & \multirow[b]{2}{*}{$N$} & \multirow[b]{2}{*}{$\%$} & \multicolumn{6}{|c|}{ Incidence rates $(1 / 100,000)$} \\
\hline & & & Ages 0-19 & Ages 20-44 & Ages 45-64 & Ages 65+ & CR & ASR $^{*}$ & & & Ages 0-19 & Ages 20-44 & Ages 45-64 & Ages 65+ & CR & ASR $^{*}$ \\
\hline Sarcoma NOS & 1,390 & 30.8 & 0.13 & 0.49 & 1.8 & 4.9 & 1.5 & 0.88 & 1,552 & 31.4 & 0.15 & 0.64 & 2.1 & 4.4 & 1.7 & 0.96 \\
\hline Osteosarcoma & 259 & 5.8 & 0.58 & 0.27 & 0.22 & 0.23 & 0.29 & 0.34 & 239 & 4.8 & 0.41 & 0.22 & 0.25 & 0.28 & 0.27 & 0.29 \\
\hline Chondrosarcoma & 91 & 2.0 & 0.08 & 0.06 & 0.13 & 0.13 & 0.10 & 0.08 & 102 & 2.1 & 0.08 & 0.07 & 0.16 & 0.14 & 0.11 & 0.09 \\
\hline Ewing's sarcoma and PNET & 48 & 1.1 & 0.12 & 0.05 & 0.04 & 0.02 & 0.05 & 0.08 & 41 & 0.83 & 0.11 & 0.05 & 0.03 & 0.01 & 0.05 & 0.07 \\
\hline Giant cell sarcoma & 111 & 2.5 & 0.06 & 0.17 & 0.12 & 0.06 & 0.12 & 0.11 & 109 & 2.2 & 0.06 & 0.17 & 0.13 & 0.06 & 0.12 & 0.10 \\
\hline Lipoblastoma & 360 & 8.0 & 0.01 & 0.14 & 0.56 & 1.1 & 0.40 & 0.23 & 274 & 5.6 & 0.02 & 0.14 & 0.44 & 0.58 & 0.30 & 0.17 \\
\hline Fibrosarcoma & 364 & 8.1 & 0.09 & 0.28 & 0.48 & 0.86 & 0.40 & 0.27 & 314 & 6.4 & 0.04 & 0.25 & 0.45 & 0.60 & 0.35 & 0.23 \\
\hline Malignant fibrohistiocytoma & 201 & 4.5 & 0.02 & 0.07 & 0.26 & 0.72 & 0.22 & 0.13 & 161 & 3.3 & 0.02 & 0.08 & 0.19 & 0.48 & 0.18 & 0.10 \\
\hline Dermatofibrosarcoma protuberans & 251 & 5.6 & 0.09 & 0.32 & 0.34 & 0.20 & 0.28 & 0.21 & 154 & 3.1 & 0.08 & 0.22 & 0.17 & 0.14 & 0.17 & 0.14 \\
\hline Vascular sarcoma & 98 & 2.2 & 0.02 & 0.02 & 0.12 & 0.39 & 0.11 & 0.06 & 94 & 1.9 & 0.02 & 0.05 & 0.13 & 0.23 & 0.10 & 0.06 \\
\hline Rhabdosarcoma & 91 & 2.0 & 0.33 & 0.03 & 0.08 & 0.11 & 0.10 & 0.18 & 62 & 1.3 & 0.18 & 0.05 & 0.04 & 0.08 & 0.07 & 0.11 \\
\hline Leiomyosarcomas & 168 & 3.7 & 0.00 & 0.06 & 0.24 & 0.56 & 0.19 & 0.10 & 441 & 8.9 & 0.02 & 0.25 & 0.77 & 0.79 & 0.49 & 0.28 \\
\hline Gastrointestinal stromal sarcoma & 663 & 14.7 & 0.00 & 0.13 & 0.97 & 2.40 & 0.74 & 0.39 & 732 & 14.8 & 0.00 & 0.13 & 1.2 & 2.1 & 0.81 & 0.40 \\
\hline Ameloblastoma & 4 & 0.09 & 0.00 & 0.00 & 0.01 & 0.00 & 0.00 & 0.00 & 4 & 0.08 & 0.00 & 0.00 & 0.00 & 0.01 & 0.00 & 0.00 \\
\hline $\begin{array}{l}\text { Malignant peripheral nerve sheath } \\
\text { tumor (MPNST) }\end{array}$ & 217 & 4.8 & 0.01 & 0.16 & 0.30 & 0.51 & 0.24 & 0.15 & 221 & 4.5 & 0.06 & 0.17 & 0.34 & 0.35 & 0.25 & 0.17 \\
\hline Synovial sarcoma & 44 & 0.98 & 0.04 & 0.05 & 0.06 & 0.04 & 0.05 & 0.05 & 43 & 0.87 & 0.01 & 0.05 & 0.06 & 0.05 & 0.05 & 0.04 \\
\hline Stromal sarcoma & 30 & 0.67 & 0.00 & 0.01 & 0.04 & 0.12 & 0.03 & 0.02 & 274 & 5.6 & 0.02 & 0.24 & 0.46 & 0.35 & 0.30 & 0.20 \\
\hline Clear cell sarcoma & 12 & 0.27 & 0.01 & 0.02 & 0.01 & 0.02 & 0.01 & 0.01 & 18 & 0.36 & 0.01 & 0.01 & 0.02 & 0.04 & 0.02 & 0.02 \\
\hline Myxosarcoma & 22 & 0.49 & 0.00 & 0.01 & 0.03 & 0.09 & 0.02 & 0.01 & 27 & 0.55 & 0.00 & 0.02 & 0.05 & 0.03 & 0.03 & 0.02 \\
\hline Malignant mesenchymoma & 57 & 1.3 & 0.01 & 0.02 & 0.08 & 0.18 & 0.06 & 0.04 & 54 & 1.1 & 0.01 & 0.03 & 0.09 & 0.11 & 0.06 & 0.03 \\
\hline Embryonic sarcoma & 1 & 0.02 & 0.01 & 0.00 & 0.00 & 0.00 & 0.00 & 0.00 & 3 & 0.06 & 0.02 & 0.00 & 0.00 & 0.00 & 0.00 & 0.01 \\
\hline Kaposi's sarcoma & 10 & 0.22 & 0.00 & 0.01 & 0.01 & 0.04 & 0.01 & 0.01 & 4 & 0.08 & 0.00 & 0.00 & 0.01 & 0.01 & 0.00 & 0.00 \\
\hline Granulosa cell sarcoma & 5 & 0.11 & 0.00 & 0.00 & 0.01 & 0.02 & 0.01 & 0.00 & 8 & 0.16 & 0.00 & 0.01 & 0.02 & 0.00 & 0.01 & 0.01 \\
\hline Alveolar soft part sarcoma (ASPS) & 6 & 0.13 & 0.02 & 0.01 & 0.00 & 0.00 & 0.01 & 0.01 & 6 & 0.12 & 0.01 & 0.02 & 0.00 & 0.00 & 0.01 & 0.01 \\
\hline Total & 4,503 & 100.0 & 1.6 & 2.4 & 5.9 & 12.6 & 5.0 & 3.4 & 4,937 & 100.0 & 1.3 & 2.9 & 7.1 & 10.9 & 5.5 & 3.5 \\
\hline
\end{tabular}

*Adjusted by the world standard population. CR, crude rate; ASR, age-standardized rate; NOS, not otherwise specified; PNET, primitive neuroectodermal tumors. 
TABLE 3 | Incidence of sarcomas by age, gender, and primary site, Shanghai, 2002-2014.

\begin{tabular}{|c|c|c|c|c|c|c|c|c|c|c|c|c|c|c|c|c|c|}
\hline \multirow[t]{3}{*}{ ICD-O } & \multirow[t]{3}{*}{ Primary sites } & \multicolumn{8}{|c|}{ Male } & \multicolumn{8}{|c|}{ Female } \\
\hline & & \multirow[b]{2}{*}{$\boldsymbol{N}$} & \multirow[b]{2}{*}{$\%$} & \multicolumn{6}{|c|}{ Incidence rates $(1 / 100,000)$} & \multirow[b]{2}{*}{$\boldsymbol{N}$} & \multirow[b]{2}{*}{$\%$} & \multicolumn{6}{|c|}{ Incidence rates $(1 / 100,000)$} \\
\hline & & & & Ages 0-19 & Ages 20-44 & Ages 45-64 & Ages 65+ & CR & ASR & & & Ages 0-19 & Ages 20-44 & Ages 45-64 & Ages 65+ & CR & ASR \\
\hline CoO-14 & Lip, oral cavity, and pharynx & 40 & 0.89 & 0.02 & 0.03 & 0.06 & 0.09 & 0.04 & 0.03 & 15 & 0.30 & 0.01 & 0.01 & 0.02 & 0.04 & 0.02 & 0.01 \\
\hline C15-26 & Digestive organs & 1,280 & 28.4 & 0.00 & 0.31 & 1.9 & 4.5 & 1.4 & 0.76 & 1,361 & 27.6 & 0.04 & 0.30 & 2.0 & 4.1 & 1.5 & 0.77 \\
\hline C16 & Stomach & 669 & 14.9 & 0.00 & 0.13 & 0.93 & 2.56 & 0.74 & 0.39 & 798 & 16.2 & 0.01 & 0.14 & 1.2 & 2.6 & 0.89 & 0.44 \\
\hline С30-39 & $\begin{array}{l}\text { Respiratory system and intrathoracic } \\
\text { organs }\end{array}$ & 210 & 4.7 & 0.05 & 0.06 & 0.32 & 0.64 & 0.23 & 0.14 & 119 & 2.4 & 0.04 & 0.10 & 0.18 & 0.17 & 0.13 & 0.09 \\
\hline C40-41 & Bone and Joint & 582 & 12.9 & 0.77 & 0.61 & 0.65 & 0.62 & 0.65 & 0.63 & 558 & 11.3 & 0.61 & 0.57 & 0.65 & 0.66 & 0.62 & 0.57 \\
\hline C44 & Skin & 274 & 6.1 & 0.09 & 0.34 & 0.34 & 0.32 & 0.30 & 0.23 & 178 & 3.6 & 0.10 & 0.23 & 0.19 & 0.24 & 0.20 & 0.16 \\
\hline C47 & $\begin{array}{l}\text { Peripheral nerve and autonomic nerve } \\
\text { system }\end{array}$ & 159 & 3.5 & 0.02 & 0.13 & 0.21 & 0.36 & 0.18 & 0.12 & 157 & 3.2 & 0.06 & 0.12 & 0.24 & 0.26 & 0.17 & 0.12 \\
\hline C48 & Retropheritoneum and peritoneum & 233 & 5.2 & 0.00 & 0.07 & 0.36 & 0.74 & 0.26 & 0.14 & 308 & 6.2 & 0.00 & 0.15 & 0.52 & 0.65 & 0.34 & 0.19 \\
\hline C49 & $\begin{array}{l}\text { Connective, subcutaneous, and other } \\
\text { soft tissues }\end{array}$ & 1,480 & 32.9 & 0.47 & 0.74 & 1.8 & 4.6 & 1.6 & 1.1 & 1,227 & 24.9 & 0.30 & 0.69 & 1.5 & 3.3 & 1.4 & 0.83 \\
\hline C50 & Breast & 7 & 0.16 & 0.00 & 0.00 & 0.01 & 0.03 & 0.01 & 0.00 & 116 & 2.4 & 0.01 & 0.10 & 0.22 & 0.10 & 0.13 & 0.08 \\
\hline C51-57 & Female genital organs & - & - & - & - & - & - & - & - & 718 & 14.5 & 0.05 & 0.49 & 1.3 & 0.96 & 0.80 & 0.49 \\
\hline C53-55 & Uterus & - & - & - & - & - & - & - & - & 618 & 12.5 & 0.03 & 0.43 & 1.2 & 0.78 & 0.69 & 0.42 \\
\hline C60-63 & Male genital organs & 75 & 1.7 & 0.07 & 0.03 & 0.09 & 0.22 & 0.08 & 0.06 & - & - & - & - & - & - & - & - \\
\hline C64-68 & Urinary tract & 61 & 1.4 & 0.05 & 0.02 & 0.08 & 0.17 & 0.07 & 0.06 & 67 & 1.4 & 0.05 & 0.02 & 0.11 & 0.14 & 0.07 & 0.06 \\
\hline C69-72 & $\begin{array}{l}\text { Eye, brain, and other parts of the } \\
\text { central nervous system }\end{array}$ & 10 & 0.22 & 0.04 & 0.01 & 0.01 & 0.01 & 0.01 & 0.02 & 11 & 0.22 & 0.03 & 0.02 & 0.00 & 0.01 & 0.01 & 0.03 \\
\hline C73-75 & Thyroid and other endocrine glands & 10 & 0.22 & 0.00 & 0.00 & 0.01 & 0.04 & 0.01 & 0.01 & 15 & 0.30 & 0.00 & 0.01 & 0.02 & 0.04 & 0.02 & 0.01 \\
\hline $\begin{array}{l}\text { C76, C77, } \\
\text { C80 }\end{array}$ & $\begin{array}{l}\text { Other sites, lymph nodes, and unknown } \\
\text { primary site }\end{array}$ & 82 & 1.8 & 0.04 & 0.03 & 0.09 & 0.29 & 0.09 & 0.06 & 87 & 1.8 & 0.02 & 0.06 & 0.13 & 0.17 & 0.10 & 0.06 \\
\hline
\end{tabular}

$C R$, crude rate; $A S R$, age-standardized rate. 
was $1.3 / 10^{5}$. Age-adjusted mortality due to sarcomas was slightly higher in males $\left(1.5 / 10^{5}\right)$ than females $\left(1.2 / 10^{5}\right)$.

Leiomyosarcoma was the most common subtype, comprising 9.9\% of all death cases, followed by lipoblastoma (6.4\%) and osteosarcoma (6.3\%). About $3.6 \%$ of sarcomas death cases occurred in children and adolescents (0-19 years), and osteosarcoma composed of $40.8 \%$ in this age group. Majority occurred in the $65+$ group with $55.5 \%$ of total death cases (Table 4).

Among those death cases, $88.1 \%$ were located in STS and $11.9 \%$ in bone and joint. The CR and ASR of mortality were $2.1 / 10^{5}$ and $1.0 / 10^{5}$ for STS, $0.3 / 10^{5}$ and $0.2 / 10^{5}$ for bone sarcomas, respectively. About $39.4 \%$ of STS death cases were from connective, subcutaneous, and other soft tissues (ICD-10: C49), followed by digestive organs (24.0\%), and retropheritoneum and peritoneum (7.9\%) (Table 5).

\section{Trends}

Figure 1 showed the trends in the incidence for all sarcomas combined, STS and bone sarcomas during 2002-2014. No significant incidence trend for all sarcomas combined was observed in males and females, with an APC of $0.3 \%$ (95\% CI: $-0.9,1.4 \%)$ and $-0.2 \%$ (95\% CI: $-1.3,1.0 \%)$ in ASRs by Joinpoint regression, respectively. The trends of incidence rates for STS and bone sarcomas were not significant for both genders. Further analysis showed that the trends of top five subgroups showed that incidence rates continued to decline during 20022014 for leiomyosarcomas, fibrosarcoma, and MPNST, while the ASR of lipoblastoma stabilized and GISS increased significantly (data not shown).

The trend in the mortality of total sarcomas during 2002-2014 increased significantly with APC 2.7\% (95\% CI: $0.7,4.7 \%$ ) for females, while it was not significant for males with APC $1.1 \%$ (95\% CI: $-1.1,3.5 \%)$. Further analysis found that the significant rising trend only existed in the ASRs for female STS with APC $2.3 \%$ (95\% CI: $0.3,4.4 \%$ ), but not for female bone sarcomas during the entire time period, as shown in Figure 2. In female, the morality rates increased but not significantly for lipoblastoma (APC 5.7, 95\% CI: -0.2, 11.1\%).

\section{DISCUSSION}

The results presented in this paper gave for the first time a comprehensive analysis focusing the incidence and mortality of sarcomas in Shanghai. The recent 2002 WHO criteria were used to recategorize histologic subtypes of sarcomas in the present study to facilitate comparison with other studies. Total 9,440 cases were diagnosed during 2002-2014 in SCR, of which 12.1\% were bone sarcomas and $87.9 \%$ were soft tissue sarcomas. The annual ASR for all sarcomas combined was $3.4 / 10^{5}$, and the ASRs for STS and bone sarcomas were $2.8 / 10^{5}$ and $0.6 / 10^{5}$, respectively.

Sarcomas account for about $1 \%$ of all malignant tumors and the total incidence $\sim 2-4$ per 100,000 population $(1,2)$. Data from CI5 showed that sarcoma incidence rates were comparable throughout much of the world (16). Previous studies that examined the incidence of sarcomas combined with STS and bone sarcomas were limited and there were marked variations in the distribution of subtypes. Population-based data on incidence of sarcomas in Europe was investigated in a study from RARECARE project (4), covering 27,908 incident cases diagnosed during 1995-2002 in the EU27 countries with crude incidence of $5.6 / 10^{5}$, of which $84 \%$ were soft tissue sarcomas and $14 \%$ were bone sarcomas, similar to our findings.

The ASR of STS in Shanghai $\left(2.8 / 10^{5}\right)$ were comparable with the report from Austrian National Cancer Registry (ASR 2.4/10 $)$ (17) and were lower than the findings from SEER program in the USA (total 5.0/10 $0^{5}$ with US 2000 standard population) (18) and from RARECARE project in Europe (total ASR 4.2/10 ${ }^{5}$ ) (4). A previous report in Beijing on STS, only including the cases diagnosed with sites of C47 and C49, showed that the incidence was lower than our findings, with CR and ASR $1.2 / 10^{5}$ and $0.9 / 10^{5}$, respectively (19). Bone sarcomas were relatively rare and the ASR $\left(0.6 / 10^{5}\right)$ in Shanghai was similar to the finding from RARECARE project in Europe (ASR 0.8/10 ${ }^{5}$ ) (4) and a report in Taiwan (ASR 0.67/10 $0^{5}$ ) (7).

The histological and molecular classification of sarcomas has been revised with the progress of new techniques, such as immunohistochemistry, multiplex PCR and sequencing, which would be reflected by the distribution and trends of histological subgroups. In this study, the three most frequent histological subtypes among STS were GISS, fibrosarcoma, and lipoblastoma, respectively. RARECARE project showed that leiomyosarcoma was the most frequent type, whereas others showed that the most common histology was liposarcoma (4). There has been a significant steadily increasing numbers of GISS in Shanghai since 2010 accounting for about range of $14.8-18.5 \%$ of all sarcomas. GISS were registered with six cases only in 2002 and varied a range of $0.4-5.9 \%$ before 2010 . One possible reason was that GISS had been diagnosed as sarcomas NOS. The total proportion of sarcomas NOS in this study was $31.2 \%$ during the entire period and the percent declined significantly since 2010, accounting for about $20 \%$. The "Chinese consensus guidelines for diagnosis and management of gastrointestinal stromal tumor" was published in 2008 and then it has received more attention with several revised edition. The application of techniques of immunohistochemistry and molecular pathology resulted in more GISS identification. Another possible explanation was that the incidence rates of leimyosarcomas decreased significantly during this period. It was reported that before using immunohistochemistry, some GISS might had been identified as leiomyosarcoma (20).

Age is an important determinant of sarcoma occurrence. Incidence of STS increases more dramatically after 50 years old. Generally, malignant bone tumors have a stable incidence rate across all ages. However, in adolescents and young adults, there is a noticeable increase (1). Similar age patterns were found in this study. A considerable variation in incidence patterns of sarcomas by histologic subtypes in this study was observed, which supported the notion that these tumors are etiologically distinct and should be considered separately in studies of potential risk factors, in accord with previous epidemiologic studies (18).

During 2002-2014, the trends in the ASRs of incidence for all sarcomas combined, STS and bone sarcomas were not significant for males and females. An upward trend in the incidence of STS overall and for females was seen in Osaka, 
TABLE 4 | Mortality of sarcomas by age, gender, and histologic type, Shanghai, 2002-2014.

\begin{tabular}{|c|c|c|c|c|c|c|c|c|c|c|c|c|c|c|c|c|}
\hline \multirow[t]{3}{*}{ Histologic group } & \multicolumn{8}{|c|}{ Male } & \multicolumn{8}{|c|}{ Female } \\
\hline & \multirow[b]{2}{*}{$N$} & \multirow[b]{2}{*}{$\%$} & \multicolumn{6}{|c|}{ Mortality rates $(1 / 100,000)$} & \multirow[b]{2}{*}{$\boldsymbol{N}$} & \multirow[b]{2}{*}{$\%$} & \multicolumn{6}{|c|}{ Mortality rates $(1 / 100,000)$} \\
\hline & & & Ages 0-19 & Ages 20-44 & Ages 45-64 & Ages 65+ & CR & ASR $^{\star}$ & & & Ages 0-19 & Ages 20-44 & Ages 45-64 & Ages 65+ & CR & ASR $^{\star}$ \\
\hline Sarcoma NOS & 888 & 40.5 & 0.09 & 0.17 & 0.90 & 4.1 & 0.99 & 0.52 & 867 & 41.5 & 0.07 & 0.21 & 0.78 & 3.5 & 0.96 & 0.46 \\
\hline Osteosarcoma & 153 & 7.0 & 0.29 & 0.12 & 0.14 & 0.26 & 0.17 & 0.18 & 117 & 5.6 & 0.20 & 0.10 & 0.08 & 0.23 & 0.13 & 0.13 \\
\hline Chondrosarcoma & 32 & 1.5 & 0.01 & 0.02 & 0.04 & 0.09 & 0.04 & 0.02 & 32 & 1.5 & 0.00 & 0.01 & 0.02 & 0.13 & 0.04 & 0.02 \\
\hline Ewing's sarcoma \& PNET & 37 & 1.7 & 0.06 & 0.04 & 0.04 & 0.02 & 0.04 & 0.05 & 30 & 1.4 & 0.06 & 0.05 & 0.01 & 0.03 & 0.03 & 0.05 \\
\hline Giant cell sarcoma & 20 & 0.91 & 0.00 & 0.02 & 0.02 & 0.06 & 0.02 & 0.01 & 16 & 0.77 & 0.01 & 0.02 & 0.02 & 0.03 & 0.02 & 0.01 \\
\hline Lipoblastoma & 157 & 7.2 & 0.00 & 0.03 & 0.19 & 0.66 & 0.17 & 0.09 & 118 & 5.7 & 0.00 & 0.02 & 0.14 & 0.44 & 0.13 & 0.06 \\
\hline Fibrosarcoma & 121 & 5.5 & 0.02 & 0.04 & 0.12 & 0.53 & 0.13 & 0.08 & 106 & 5.1 & 0.01 & 0.01 & 0.10 & 0.46 & 0.12 & 0.05 \\
\hline Malignant fibrohistiocytoma & 121 & 5.5 & 0.01 & 0.01 & 0.13 & 0.60 & 0.13 & 0.07 & 94 & 4.5 & 0.00 & 0.02 & 0.08 & 0.40 & 0.10 & 0.05 \\
\hline Dermatofibrosarcoma protuberans & 22 & 1.0 & 0.01 & 0.01 & 0.02 & 0.10 & 0.02 & 0.01 & 15 & 0.72 & 0.00 & 0.00 & 0.01 & 0.08 & 0.02 & 0.01 \\
\hline Vascular sarcoma & 68 & 3.1 & 0.00 & 0.01 & 0.07 & 0.33 & 0.08 & 0.04 & 41 & 2.0 & 0.01 & 0.00 & 0.06 & 0.13 & 0.05 & 0.02 \\
\hline Rhabdosarcoma & 56 & 2.6 & 0.20 & 0.02 & 0.04 & 0.08 & 0.06 & 0.10 & 45 & 2.2 & 0.06 & 0.04 & 0.03 & 0.10 & 0.05 & 0.05 \\
\hline Leiomyosarcomas & 151 & 6.9 & 0.00 & 0.03 & 0.14 & 0.74 & 0.17 & 0.09 & 274 & 13.1 & 0.00 & 0.08 & 0.40 & 0.81 & 0.30 & 0.15 \\
\hline Gastrointestinal stromal sarcoma & 148 & 6.8 & 0.00 & 0.01 & 0.11 & 0.84 & 0.16 & 0.08 & 104 & 5.0 & 0.00 & 0.01 & 0.07 & 0.52 & 0.12 & 0.04 \\
\hline Ameloblastoma & 1 & 0.05 & 0.00 & 0.00 & 0.00 & 0.01 & 0.00 & 0.00 & 0 & 0.00 & 0.00 & 0.00 & 0.00 & 0.00 & 0.00 & 0.00 \\
\hline $\begin{array}{l}\text { Malignant peripheral nerve sheath } \\
\text { tumor (MPNST) }\end{array}$ & 113 & 5.2 & 0.02 & 0.04 & 0.12 & 0.48 & 0.13 & 0.07 & 94 & 4.5 & 0.03 & 0.04 & 0.11 & 0.28 & 0.10 & 0.06 \\
\hline Synovial sarcoma & 24 & 1.1 & 0.01 & 0.02 & 0.04 & 0.04 & 0.03 & 0.02 & 24 & 1.2 & 0.01 & 0.03 & 0.04 & 0.03 & 0.03 & 0.02 \\
\hline Stromal sarcoma & 13 & 0.59 & 0.00 & 0.00 & 0.02 & 0.05 & 0.01 & 0.01 & 64 & 3.1 & 0.00 & 0.01 & 0.08 & 0.22 & 0.07 & 0.03 \\
\hline Clear cell sarcoma & 7 & 0.32 & 0.00 & 0.01 & 0.01 & 0.02 & 0.01 & 0.00 & 10 & 0.48 & 0.01 & 0.01 & 0.01 & 0.03 & 0.01 & 0.01 \\
\hline Myxosarcoma & 13 & 0.59 & 0.00 & 0.00 & 0.01 & 0.07 & 0.01 & 0.01 & 6 & 0.29 & 0.00 & 0.00 & 0.01 & 0.01 & 0.01 & 0.00 \\
\hline Malignant mesenchymoma & 35 & 1.6 & 0.00 & 0.00 & 0.05 & 0.14 & 0.04 & 0.02 & 22 & 1.1 & 0.01 & 0.01 & 0.03 & 0.06 & 0.02 & 0.01 \\
\hline Embryonic sarcoma & 0 & 0.00 & 0.00 & 0.00 & 0.00 & 0.00 & 0.00 & 0.00 & 1 & 0.05 & 0.01 & 0.00 & 0.00 & 0.00 & 0.00 & 0.00 \\
\hline Kaposi's sarcoma & 4 & 0.18 & 0.00 & 0.00 & 0.00 & 0.02 & 0.00 & 0.00 & 2 & 0.10 & 0.00 & 0.00 & 0.00 & 0.01 & 0.00 & 0.00 \\
\hline Granulosa cell sarcoma & 3 & 0.14 & 0.00 & 0.00 & 0.00 & 0.02 & 0.00 & 0.00 & 2 & 0.10 & 0.00 & 0.00 & 0.01 & 0.00 & 0.00 & 0.00 \\
\hline Alveolar soft part sarcoma (ASPS) & 4 & 0.18 & 0.01 & 0.00 & 0.00 & 0.02 & 0.00 & 0.00 & 4 & 0.19 & 0.00 & 0.01 & 0.00 & 0.00 & 0.00 & 0.00 \\
\hline Total & 2,191 & 100.0 & 0.72 & 0.60 & 2.2 & 9.3 & 2.4 & 1.5 & 2,088 & 100.0 & 0.49 & 0.67 & 2.1 & 7.5 & 2.3 & 1.2 \\
\hline
\end{tabular}

*Adjusted by the world standard population. CR, crude rate; ASR, age-standardized rate; NOS, not otherwise specified; PNET, primitive neuroectodermal tumors. 
TABLE 5 | Mortality of sarcomas by age, gender, and primary site, Shanghai, 2002-2014.

\begin{tabular}{|c|c|c|c|c|c|c|c|c|c|c|c|c|c|c|c|c|c|}
\hline \multirow[t]{3}{*}{ ICD-O } & \multirow[t]{3}{*}{ Primary sites } & \multicolumn{8}{|c|}{ Male } & \multicolumn{8}{|c|}{ Female } \\
\hline & & \multirow[b]{2}{*}{$N$} & \multirow[b]{2}{*}{$\%$} & \multicolumn{6}{|c|}{ Mortality rates $(1 / 100,000)$} & \multirow[b]{2}{*}{$\boldsymbol{N}$} & \multirow[b]{2}{*}{$\%$} & \multicolumn{6}{|c|}{ Mortality rates $(1 / 100,000)$} \\
\hline & & & & Ages 0-19 & Ages 20-44 & Ages 45-64 & Ages 65+ & CR & ASR & & & Ages 0-19 & Ages 20-44 & Ages 45-64 & Ages 65+ & CR & ASR \\
\hline C0O-14 & Lip, oral cavity, and pharynx & 24 & 1.1 & 0.00 & 0.01 & 0.03 & 0.09 & 0.03 & 0.01 & 6 & 0.29 & 0.00 & 0.01 & 0.00 & 0.03 & 0.01 & 0.00 \\
\hline C15-26 & Digestive organs & 501 & 22.9 & 0.00 & 0.07 & 0.47 & 2.5 & 0.56 & 0.27 & 405 & 19.4 & 0.02 & 0.06 & 0.28 & 1.91 & 0.45 & 0.19 \\
\hline C16 & Stomach & 206 & 9.4 & 0.00 & 0.02 & 0.15 & 1.2 & 0.23 & 0.11 & 194 & 9.3 & 0.00 & 0.03 & 0.09 & 1.00 & 0.22 & 0.08 \\
\hline С30-39 & $\begin{array}{l}\text { Respiratory system and intrathoracic } \\
\text { organs }\end{array}$ & 152 & 6.9 & 0.03 & 0.03 & 0.20 & 0.56 & 0.17 & 0.09 & 74 & 3.5 & 0.02 & 0.05 & 0.12 & 0.13 & 0.08 & 0.05 \\
\hline C40-41 & Bone and Joint & 286 & 13.1 & 0.37 & 0.21 & 0.29 & 0.60 & 0.32 & 0.29 & 225 & 10.8 & 0.23 & 0.16 & 0.17 & 0.60 & 0.25 & 0.19 \\
\hline C44 & Skin & 36 & 1.6 & 0.01 & 0.01 & 0.02 & 0.21 & 0.04 & 0.02 & 26 & 1.3 & 0.00 & 0.00 & 0.02 & 0.13 & 0.03 & 0.01 \\
\hline C47 & $\begin{array}{l}\text { Peripheral nerve and autonomic nerve } \\
\text { system }\end{array}$ & 78 & 3.6 & 0.00 & 0.03 & 0.08 & 0.32 & 0.09 & 0.05 & 77 & 3.7 & 0.05 & 0.04 & 0.08 & 0.21 & 0.09 & 0.06 \\
\hline C48 & Retropheritoneum and peritoneum & 161 & 7.4 & 0.00 & 0.03 & 0.21 & 0.65 & 0.18 & 0.09 & 175 & 8.4 & 0.00 & 0.05 & 0.25 & 0.53 & 0.19 & 0.10 \\
\hline C49 & $\begin{array}{l}\text { Connective, subcutaneous and other } \\
\text { soft tissues }\end{array}$ & 805 & 36.7 & 0.21 & 0.17 & 0.75 & 3.8 & 0.89 & 0.52 & 681 & 32.6 & 0.10 & 0.20 & 0.53 & 2.83 & 0.76 & 0.37 \\
\hline C50 & Breast & 3 & 0.14 & 0.00 & 0.00 & 0.00 & 0.01 & 0.00 & 0.00 & 40 & 1.9 & 0.00 & 0.01 & 0.06 & 0.11 & 0.04 & 0.02 \\
\hline C51-57 & Female genital organs & - & - & - & - & - & - & - & - & 290 & 13.9 & 0.01 & 0.06 & 0.48 & 0.76 & 0.32 & 0.16 \\
\hline C53-55 & Uterus & - & - & - & - & - & - & - & - & 238 & 11.4 & 0.00 & 0.05 & 0.42 & 0.58 & 0.26 & 0.13 \\
\hline C60-63 & Male genital organs & 36 & 1.6 & 0.05 & 0.01 & 0.03 & 0.12 & 0.04 & 0.03 & - & - & - & - & - & - & - & - \\
\hline C64-68 & Urinary tract & 43 & 2.0 & 0.02 & 0.01 & 0.06 & 0.16 & 0.05 & 0.03 & 30 & 1.4 & 0.02 & 0.00 & 0.03 & 0.10 & 0.03 & 0.02 \\
\hline C69-72 & $\begin{array}{l}\text { Eye, brain, and other parts of the } \\
\text { central nervous system }\end{array}$ & 9 & 0.41 & 0.03 & 0.01 & 0.01 & 0.01 & 0.01 & 0.02 & 9 & 0.43 & 0.02 & 0.02 & 0.00 & 0.01 & 0.01 & 0.02 \\
\hline C73-75 & Thyroid and other endocrine glands & 6 & 0.27 & 0.00 & 0.00 & 0.01 & 0.02 & 0.01 & 0.00 & 10 & 0.48 & 0.00 & 0.00 & 0.01 & 0.04 & 0.01 & 0.01 \\
\hline $\begin{array}{l}\mathrm{C} 76, \mathrm{C} 77 \\
\mathrm{C} 80\end{array}$ & $\begin{array}{l}\text { Other sites, lymph nodes and } \\
\text { unknown primary site }\end{array}$ & 51 & 2.3 & 0.01 & 0.01 & 0.04 & 0.26 & 0.06 & 0.03 & 40 & 1.9 & 0.02 & 0.01 & 0.05 & 0.12 & 0.04 & 0.02 \\
\hline
\end{tabular}

$C R$, crude rate; $A S R$, age-standardized rate. 

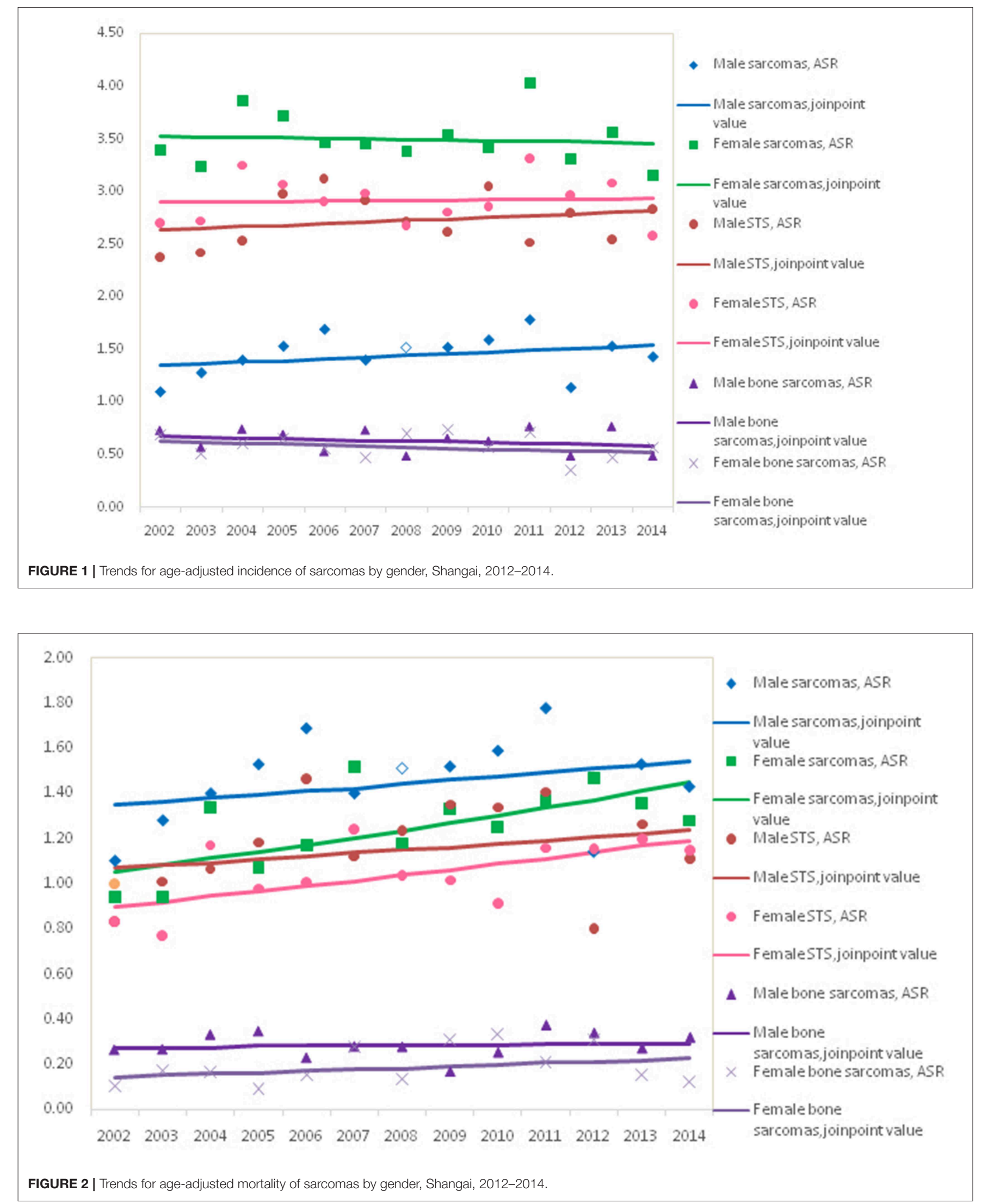
Japan during 1978-2007 (21). However, a population-based epidemiologic study in Austria for the period 1984-2004 (17) has not confirmed the increasing incidence rates of STS. It mentioned that different inclusion criteria (such as Kaposi's sarcoma and dermatofibrosarcoma) and classifications in the various studies would explain the increase of incidence in some studies rather than true increase of STS due to new or accumulated risk factors (17).

The causes of most sarcomas are unknown. Both genetic and environmental factors likely contribute to the etiology of sarcomas $(1,8,21)$. The rarity of the disease combined with the diverse number of subtypes make sarcomas difficulty to study and the epidemiology and etiology of sarcomas are not well-understood. Environmental factors that increase sarcoma risk include radiation exposure and chemical carcinogens (8). Ionizing radiation exposure, especially by means of radiotherapy for a previous cancer, has been shown to be strongly associated with secondary sarcoma development (1, 22). There was an increasing incidence of second sarcomas among cancer survivors, and one may speculate a relation to the intensified use of cytotoxic treatment of the preceding malignancy (23). Other risk factors include occupational exposure to certain chemicals, including herbicides such as phenoxyacetic acids. HIV-positive individuals have an increased risk for Kaposi's sarcoma. Several familial cancer syndromes confer sarcoma pre-disposition, such as the LFS (8). No study has been implemented in Shanghai about the risk factors of sarcomas and these data serve to illustrate the complexity of sarcomas.

To our knowledge, no population-based study to date has evaluated the mortality of sarcomas for all types combined and the histological subtypes. In this study, the ASR for mortality of sarcomas combined was $1.3 / 10^{5}$ and the ASRs of mortality for STS and bone sarcomas were $1.0 / 10^{5}$ and $0.2 / 10^{5}$, respectively. For STS, except for the sarcomas NOS, leiomyosarcomas was the most common subtype among death cases of sarcomas and majority occurred in the old over $65+$ years. For bone sarcomas, about $40 \%$ of cases occurred in children and adolescents (019 years).

No substantial changes were found in the mortality rates of sarcomas combined and bone sarcomas for males and females. However, a modest significant increase in average annual mortality rates (APC, 2.3\%; 95\% CI: 0.3, 4.4\%) was observed for STS among females, not males. The mortality increasing of female STS was maybe due to in part to the distribution change of subtypes and the poor survival of lipoblastoma in females. One should be noticed that some of sarcoma subgroups were very rare and varied a lot with a wide range of $95 \%$ CI. A study from a medical unit in UK showed that there had been no significant change in 1 year mortality rate of STS during 1985-2010, and TNM stage was a useful predictor (24). Survival studies on sarcomas and its subgroups are warranted.

This study included the sarcomas at all sites including skin and visceral sarcomas, and not only bone and soft tissue tumors. SCR was a population-based registry and has been a regular contributor to the CI5. The quality of data in this report was high with $94.4 \%$ of $\mathrm{MV}$. Otherwise, there were several potential limitations in our study. The use of new techniques may be systematically under- or over-represented, which influenced the patterns and the trends. There was evidence that the gold standard pathologic diagnosis was not consistently reliable for sarcomas and the chances to misclassify the histology for a pathologist also existed $(8,25,26)$ Although this study focused on the data after 2002 and some advent of ancillary technologies, such as immunohistochemistry and molecular genetics/molecular cytogenetics, had been applied in Shanghai, there were over $30 \%$ of sarcomas NOS in this study. It's a good point that the proportion of sarcomas NOS reduced to about $20 \%$ after 2010. In addition, as previously described, some of the sarcoma subtypes are uncommon and generalizations concerning incidence and mortality rates are difficult to make.

The diversity and rarity of sarcomas suggested that a cooperative networking in prevention, diagnosis, therapy, and research for this rare type of cancers was warranted. With the ongoing collection of the sarcoma cases, accumulative detailed information may reveal more subtle etiologic clues and provide more evidence for decision on effective therapy.

\section{ETHICS STATEMENT}

The study was approved and the need for consent was waived by the institutional review board (IRB) of Shanghai Municipal Center for Disease Control and Prevention. In this study, only data in annual cancer report was used and no information to identify individual subjects was included.

\section{AUTHOR CONTRIBUTIONS}

FC, YY, BP, ZY, and LW contributed conception and design of the study. WChunx, WChunf, and BP collected and organized the database. BP and WChunx performed the statistical analysis. BP and ZY draft the manuscript. SY, ZC, XJ, LJ, KL, CZ, and ZW revised and made the decision to submit for publication. All authors contributed to manuscript revision, read, and approved the submitted version.

\section{FUNDING}

This work was supported by 3 year Action Plan on Public Health, Phase IV, Shanghai, China (15GWZK0801).

\section{ACKNOWLEDGMENTS}

We thank Dr. Zheng Ying and Zhou Changming at Shanghai Tumor Hospital affiliated to Fudan University for helpful comments on pathology classification. We thank the staffs who continuously provide case reports and case follow-up in all related hospitals and district CDC. We thank the staffs in the department of Vital Statistics for the help of death information. 


\section{REFERENCES}

1. Burningham Z, Hashibe M, Spector L, Schiffman JD. The epidemiology of sarcoma. Clin Sarcoma Res. (2012) 2:14. doi: 10.1186/2045-3329-2-14

2. Siegel RL, Miller KD, and Jemal A. Cancer statistics, 2015. CA Cancer J Clin. (2015) 65:5-29. doi: 10.3322/caac.21254

3. U. K. Fletcher CDM, Metens F. World Health Organization Classification of Tumors. Pathology and Genetics of Tumors of Soft Tissue and Bone. Lyon: IARC Press. (2002).

4. Stiller CA, Trama A, Serraino D, Rossi S, Navarro C, Chirlaque MD, et al. Descriptive epidemiology of sarcomas in Europe: report from the RARECARE project. Eur J Cancer. (2013) 49:684-95. doi: 10.1016/j.ejca.2012. 09.011

5. Hui JY. Epidemiology and etiology of sarcomas. Surg Clin North Am. (2016) 96:901-14. doi: 10.1016/j.suc.2016.05.005

6. Ducimetiere F, Lurkin A, Ranchere-Vince D, Decouvelaere AV, Peoc'h M, Istier L, et al. Incidence of sarcoma histotypes and molecular subtypes in a prospective epidemiological study with central pathology review and molecular testing. PLOS ONE. (2011) 6:e20294. doi: 10.1371/journal.pone.0020294

7. Hung GY, Horng JL, Yen HJ, Yen CC, Chen WM, Chen PC, et al. Incidence patterns of primary bone cancer in taiwan (2003-2010): a populationbased study. Ann Surg Oncol. (2014) 21:2490-8. doi: 10.1245/s10434-0143697-3

8. Thomas DM, Ballinger ML. Etiologic, environmental and inherited risk factors in sarcomas. J Surg Oncol. (2015) 111:490-5. doi: 10.1002/jso.23809

9. Lahat G, Lazar A, Lev D. Sarcoma epidemiology and etiology: potential environmental and genetic factors. Surg Clin North Am. (2008) 88:451-81. doi: 10.1016/j.suc.2008.03.006

10. Fletcher C, Bridge J, Hogendoorn P, Mertens F. International Agency for Research on Cancer. WHO Classification of Tumours of Soft Tissue and Bone. 4th ed. International Agency for Research on Cancer (IARC) (2013). p. 281-95.

11. Jin F, Devesa SS, Zheng W, Blot WJ, Fraumeni JF Jr, Gao YT. Cancer incidence trends in urban Shanghai, 1972-1989. Int J Cancer. (1993) 53:764-70.

12. Bao PP, Zheng Y, Wang CF, Gu K, Jin F, Lu W. Time trends and characteristics of childhood cancer among children age 0-14 in Shanghai. Pediatr Blood Cancer. (2009) 53:13-6. doi: 10.1002/pbc.21939

13. Waterhouse J, Muir C, Shanmugaratnam K, Powell J. Cancer incidence in five continents. Vol IV. Lyon: IARC (1982).

14. Kim HJ, Fay MP, Feuer EJ, Midthune DN. Permutation tests for joinpoint regression with applications to cancer rates. Stat Med. (2000) 19:335-51. doi: 10.1002/(SICI)1097-0258(20000215)19:3<335::AID-SIM336>3.0.CO;2-Z

15. National Cancer Institute. Joinpoint Regression Program. Version 4.0.4. (2013). Available online at: http://surveillance.cancer.gov/joinpoint/ (accessed July 01, 2017).

16. Curado M, Edwards B, Shin H, Strom H, Ferlay J, Heanue M, Boyle P. In Cancer Incidence in Five Continents, Vol. IX. IARC Scientific Publications No. 160. Lyon: IARC (2007).
17. Wibmer C, Leithner A, Zielonke N, Sperl M, Windhager $\mathrm{R}$. Increasing incidence rates of soft tissue sarcomas? A population-based epidemiologic study and literature review. Ann Oncol. (2010) 21:1106-11. doi: 10.1093/annonc/mdp415

18. Toro JR, Travis LB, Wu HJ, Zhu K, Fletcher CD, Devesa SS. Incidence patterns of soft tissue sarcomas, regardless of primary site, in the surveillance, epidemiology and end results program, 1978-2001: An analysis of 26,758 cases. Int J Cancer. (2006) 119:2922-30. doi: 10.1002/ijc.22239

19. Yang L, Fang ZW, Fan ZF, Wang N, Yuan YN, Li HC, Liu S. An analysis of incidence trends and characteristics of soft tissue sarcoma in Beijing, 1999-2013. Zhonghua Zhong Liu Za Zhi. (2017) 39:471-6. doi: 10.3760/cma.j.issn.0253-3766.2017.06.013

20. Nomura E, Ioka A, Tsukuma $\mathrm{H}$. Incidence of soft tissue sarcoma focusing on gastrointestinal stromal sarcoma in Osaka, Japan, during 1978-2007. Jpn J Clin Oncol. (2013) 43:841-5. doi: 10.1093/jjco/hyt073

21. Helman LJ, Meltzer P. Mechanisms of sarcoma development. Nat Rev Cancer. (2003) 3:685-94. doi: 10.1038/nrc1168

22. Rubino C, Shamsaldin A, Le MG, Labbe M, Guinebretiere JM, Chavaudra J, de Vathaire F. Radiation dose and risk of soft tissue and bone sarcoma after breast cancer treatment. Breast Cancer Res Treat. (2005) 89:277-88. doi: 10.1007/s10549-004-2472-8

23. Bjerkehagen B, Smastuen MC, Hall KS, Skjeldal S, Bruland OS, Smeland S, et al. Incidence and mortality of second sarcomas-a population-based study. Eur J Cancer. (2013) 49:3292-302. doi: 10.1016/j.ejca.2013.05.017

24. Nandra R, Hwang N, Matharu GS, Reddy K, Grimer R. One-year mortality in patients with bone and soft tissue sarcomas as an indicator of delay in presentation. Ann $R$ Coll Surg Engl. (2015) 97:425-33. doi: 10.1308/003588415X14181254790284

25. Mastrangelo G, Coindre JM, Ducimetiere FA, Dei Tos P, Fadda E, Blay JY, et al. Incidence of soft tissue sarcoma and beyond: a populationbased prospective study in 3 European regions. Cancer. (2012) 118:5339-48. doi: $10.1002 / \mathrm{cncr} .27555$

26. Al-Ibraheemi A, Folpe AL. Voluntary second opinions in pediatric bone and soft tissue pathology: a retrospective review of 1601 cases from a single mesenchymal tumor consultation service. Int J Surg Pathol. (2016) 24:685-91. doi: $10.1177 / 1066896916657591$

Conflict of Interest Statement: The authors declare that the research was conducted in the absence of any commercial or financial relationships that could be construed as a potential conflict of interest.

Copyright (c) 2019 Pingping, Yuhong, Weiqi, Chunxiao, Chunfang, Yuanjue, Chenping, Jianru, Jiade, Lin, Zhengdong, Weibin, Chen and Yang. This is an openaccess article distributed under the terms of the Creative Commons Attribution License (CC BY). The use, distribution or reproduction in other forums is permitted, provided the original author(s) and the copyright owner(s) are credited and that the original publication in this journal is cited, in accordance with accepted academic practice. No use, distribution or reproduction is permitted which does not comply with these terms. 